\title{
CRIME IN RELATION TO THE STATE AND TO MUNICIPALITIES
}

\author{
EUGENE SMITH, ESQ. \\ New York City
}

The federal government has jurisdiction in the case of crimes committed against the United States, but this jurisdiction is wholly distinct from the criminal jurisdiction vested in the several states of the Union. With this federal exception, all criminal law in this country has its sole source and authority in the sovereign power of the state. The state is territorially divided into counties and subdivided into towns, cities and villages; but all these local subdivisions are created by the state. For convenience in the administration of government, these localized political units are vested with certain powers; still, it is true that all the powers they possess are granted and delegated to them by the central sovereignty of the state. Thus the state is the fons et origo of all criminal as well as of all civil jurisdiction.

This supremacy of the state involves, for the purposes of the present discussion, four elements: the state has the sole power (I) to enact all criminal laws; (2) to enforce those laws by the detection and arrest of offenders; (3) to try judicially, and to convict or acquit, persons accused of crime; and (4) to inflict the penalties prescribed by law.

All these powers are delegated by the state, to a greater or less extent, to the counties towns, cities, and villages (all of which are comprised under the term "municipal corporations," and are herein designated as "municipalities"); and it is the object of the present paper to discuss the question to what extent such delegation of power is necessary and proper, and to determine in what cases the power ought to be, not delegated, but exercised by the state itself. The four powers above enumerated will be considered separately and in the order in which they have been stated. 


\section{CRIMINAL LEGISLATION}

The power is delegated to municipal corporations to enact ordinances and regulations, and to enforce them by fines and penalties. These ordinances and regulations have all the force of law and as their violation is a misdemeanor, they form a part of the body of criminal law. To delegate the power to enact criminal laws may seem, prima facie, an improper and dangerous transference of sovereignty. The municipal power thus conferred, however, is strictly limited and defined by statute. There are countless subjects, affecting the public health and orderly living, that demand regulation in accordance with the varied circumstances and local diversities of separate communities; these subjects cannot be adequately covered by a general statute of universal application, nor can they be wisely treated by special statutes relating to each separate community. It is impossible for the state legislature to act with that accurate knowledge of the local needs of a municipality in its internal life which the municipality itself possesses and which is the essential basis of salutary legislation. "Home rule" for municipalities is a political principle which stands in no danger of being carried to excess, and sound government demands rather its extension than its repression. Perhaps the strongest argument in favor of it rests in its tendency to increase the power and dignity of citizenship; by intrusting the well-being of the municipality to the keeping of its own citizens, it serves to develop in them a sense of individual responsibility for good government, an intelligent interest in public affairs, and a conviction of civic duty - sentiments which a strictly paternal government by the state tends to deaden.

\section{DETECTION AND ARREST OF OFFENDERS}

The detection of crime and the arrest of persons accused of crime are delegated almost exclusively to the municipalities. A thorough enforcement of the laws can be secured only through the loyal co-operation of the whole community. It needs, not alone a public opinion in favor of the laws, but a public opinion which imposes on every man the personal duty of rendering aid and co-operation in enforcing the law, and holds one guilty of 
complicity who being cognizant of a crime, maintains silence or shrinks from giving testimony. The most effectual enforcement of the laws will result from laying upon each local community the responsibility of securing its own protection against crime. Municipal action is likely to be more drastic and effective than any system by which the duty of detection and arrest is centered in some department of the state government.

THE TRIAL OF PERSONS ACCUSED OF CRIME

From the delegation to the municipality of power to enact ordinances the violation of which is a misdemeanor, it is a natural step to invest the municipal courts with power to try, and to pronounce sentence upon, those who disobey such ordinances. The culprit in such case is an offender against the municipality, which ought, logically to be clothed with jurisdiction to enforce its own enactments. The liberty of the individual is sufficiently protected if in every case an appeal lies from the municipal courts to those of the state.

But the case of persons accused of violating the penal laws of the state is widely different. Such a person, if guilty, is an offender against the state, and should be dealt with solely by the courts of the state. The state has no higher function than to guard the personal liberty of every law-abiding citizen on the one hand, and on the other to protect the whole community against crime. When a person accused is brought to trial, he is the defendant, with the presumption of innocence in his favor, and the people of the state are the plaintiffs; if the accused be innocent, his right of personal liberty is put at jeopardy by the trial; if he is guilty, the safety of the whole community is at stake in the trial. When issues of such momentous importance are involved, the state is called upon to use the highest powers that pertain to its sovereignty; it has no right to delegate such powers and duties to any inferior tribunal. The courts of the state, embodying the supreme judicial power of the state, are alone competent to assume the responsibility of deciding whether a person has violated a penal law of the state - a responsibility equally great whether the judgment be one of conviction or of acquittal. 
Another reason why the state courts alone should be invested with criminal jurisdiction is found in the fact that such exclusive jurisdiction tends to secure uniformity in the administration of criminal law. A person now arraigned may secure acquittal through the rulings of any court excluding certain evidence, while in another court a different ruling would result in conviction; or, if found guilty, a prisoner may receive a sentence of thirty days in one court, and another prisoner under the same circumstances in another court may receive a sentence of three years. These gross divergences between different tribunals in the conduct of trials and in the length of sentences imposed cast disrepute upon the administration of justice and weaken the force of the criminal law. If all criminal trials were confined to the state courts such inequalities and inconsistencies would in great measure disappear. For the state courts, though separated from each other locally, have equal and concurrent jurisdiction and collectively constitute, practically, one court; in recognition of this fact, their judges have always aimed at a harmonious procedure; there is a body of practice, of precedent, of tradition, which constantly tends to effect, and does largely effect, a certain unity in judicial thought and action among these co-ordinate courts. The beneficial effect of this unity is now observable in such criminal cases as come to trial in the state courts. Most of the incongruities and contradictions that mar the administration of the criminal law arise from the clashing of the inferior municipal courts.

\section{IMPRISONMENT}

There are two kinds of imprisonment, widely different in their nature and object: imprisonment after sentence, which is punitive, and imprisonment before sentence and while awaiting trial, which is a mere continuation of the arrest having no penal feature, but aiming simply at the safe custody of the prisoner. These two forms of imprisonment require wholly different modes of treatment and must be considered separately.

I. Imprisonment after sentence.-It is now universally admitted that the state imprisons the convict from no motive of vengeance or retribution. $\mathrm{He}$ is imprisoned for precisely the 
same reason that demands the forcible confinement of persons affected by violent insanity or contagious disease, whom it is dangerous to the community to have at large; so the protection of the community constitutes the sole motive and justification for putting a convict in prison. Such protection is secured so long as the incarceration continues. But incarceration differs in its effect from quarantine against contagion, for example. When the quarantine has continued long enough, the danger of contagion often becomes extinct. Mere incarceration, however, no matter how long it continues, has no tendency to produce any improvement in the character of the convict; on the contrary, experience shows that its tendency is hardening and demoralizing. Imprisonment without reformative training affords protection to the public only so long as it lasts; and when the convict is discharged, he becomes the source of greater danger to the community than ever before. Reformation alone yields a protection which is both effective and lasting.

All this is rudimentary and not calculated to excite serious discussion. The only difficulty is in a widespread incredulity as to the possibility of reforming a convict by any measure of prison discipline. The reformation of a criminal is popularly regarded as a visionary delusion, a chimera. This skepticism is susceptible of ready explanation; it rests upon the total lack of popular information regarding the reformative methods that have been tested and approved, and regarding the results that have been actually attained. These methods and their supposed operation are generally viewed as a recondite subject, not easy of comprehension, the fabric of fanciful ideals by optimistic and unpractical philanthropists.

In fact, however, the principles underlying reformative measures are quite simple, and the methods used in their application have been developed by experiment and by careful observation of the tangible results. Nothing can be more practical than the modern reformatory system of treating convicts; and the evolution of that system has proceeded along lines strictly scientificscientific in the sense that every step in the development of the system has been tested by the practical effects of actual experi- 
ment. The proof of any system is in its results; the statistics of the New York State Reformatory at Elmira, where the new system, so far as this country is concerned, had its origin, and the statistics of other reformatories in other states, show that about 80 per cent. of the convicts there treated have been actually reclaimed and transformed from felons into law-abiding members of the free community. Results, the same in kind if not in degree, have been reached at Mettrai in France, in Spain by Montesinos, in Ireland by Sir Walter Crofton, in Munich by Obermaier, at the Rauhe Haus in Germany by Wichern and his successors; and the Elmira system has now been introduced and is in operation in Japan.

Without entering upon the details of this reformatory system, the magnitude and importance of the results it has accomplished are indisputable. They compel the conclusion that every prisoner convicted of crime ought to be subjected to the disciplinary treatment which has proved effective with the large majority of those to whom it has been applied, with the hope of accomplishing his reformation. This conclusion rests not on philanthropic reasons only; it is dictated by sound governmental policy; reformation is the only possible protection of the public against the discharged convict.

Here then, is a vast responsibility and an imperative duty imposed upon the state: to make all prisons within its borders reformatory in character; to give the public the benefit of the application of reformative treatment to every person convicted of crime and sentenced to imprisonment. Under the nonreformative system of imprisonment, which is now the prevailing system, the states turn loose upon the country every year an army of desperate criminals, thus replenishing the criminal class and furnishing it with leaders and expert instructors in crime; the discharged convict is the anomaly and the despair of modern civilization. In reformation lies the hope of the future in the struggle against crime.

The establishment of such a reformative system, extending to all convict prisoners within a state, is manifestly an enterprise which the state alone is competent to undertake. From the 
nature of the case, it cannot be delegated to the municipalities. A reformatory conducted on approved lines is a costly institution; it requires, for many reasons, an extensive equipment. The cornerstone of the reformative system is industrial training, and a cardinal principal in its administration is the individual treatment of convicts. A reformatory can achieve success only under the management of skilled experts, who are thoroughly versed in the approved modern systems of prison discipline, in the methods employed and the results attained; who have tact in dealing with prisoners and insight in observing their individual characteristics; they must have the power of detecting the special weakness and the peculiar aptitude of each prisoner, and must adapt the treatment to the individual requirements of each case. This demands an extensive variety of industrial trades and employments, fitted to widely differing capabilities and each of these industrial departments must be manned with a corps of competent instructors and overseers. Again, in many cases it is found that the criminal tendency can be traced to some physical defect, or to some abnormal, or arrested, development of the mind or of the moral sense. In treating such cases, some most interesting experiments made at Elmira have demonstrated that a sane body tends to develop a sane mind; strengthening of the body has been followed by brightening of the mind. To this end, baths, massage, and athletic exercises have worked wonders, and Elmira has for some years been equipped with Turkish baths and a large gymnasium. To effect a rounded development, intellectual and moral education are an essential accompaniment of industrial training, and schools of trades must be supplemented by schools of letters, all under the management of skilled instructors.

Enough, perhaps, has been said to show that an effective reformatory prison involves an expensive plant and a large and varied equipment; more than this, it must be manned by a corps of experts who know how to handle convicts with a single view to their reformation. This is too large an enterprise for a municipality to undertake; it is quite beyond municipal resources, except in the case of a few very large cities; it is outside the proper scope of a municipality which resembles a business cor- 
poration and deals mainly with the material interests of the community. The state alone has the resources in men and in money requisite to carry on an enterprise so broad in character and important in results as the maintenance of a reformative prison system. This, as a measure of public protection affecting all the inhabitants of the state, logically comes within the highest function of the state. The state cannot abdicate this supreme duty and delegate it to the municipalities with any more fitness than it can commit to the counties of the state the control of its military state guard.

Uniformity of prison administration is essential to the successful operation of a reformatory system. If one prison treats its convicts with greater severity or allows them fewer privileges than another prison does, a sense of the injustice of such inequality tends to counteract reformative influences. It is characteristic of the criminal to regard himself an injured person; the only way in which he tries to justify to himself the depredations he commits upon the public is by the fancy that the public has not dealt justly by him; he becomes embittered against society by nursing the belief that he has not had a fair chance in life, and he sets his hand against every man because he imagines that every man's hand has been set against him. To cure this morbid state of the mind, nothing is more indispensable in the administration of prisons than a discipline which is inflexible and uniform. Such uniformity of administration can be secured only by bringing all the prisons in a state under the direction and control of a central authority. It must not be forgotten that a reformatory system is, and always must be, a growing and developing system. It advances by tentative methods; new experiments will constantly be tried and the results carefully tested. By this scientific method, existing systems have reached their present stage of development, and by the same method their future evolution must proceed. In this view, the advantages of centralization are sufficiently obvious. All the prisons in the state are then working in perfect harmony toward the same end; experiments receive a broader and more conclusive testing; a successful measure secures universal adoption; and every con- 
victed prisoner within the limits of the state is subjected to the reforming influences of the most approved system of treatment.

The administration of prisons, under the system, or lack of system, now prevailing, is of a miscellaneous and haphazard character. Some are under state control, some under municipal control, some under private charitable management and others are under a mixed charge, partly private and partly public. In the state of New York, for example, there are three state prisons, five reformatories, and one industrial school under the exclusive control of the state; there are six penitentiaries under the exclusive control of the counties where they are severally located; there is a county jail in each of the counties of the state under the exclusive control of the county; and then there are numerous city prisons, houses of refuge, juvenile asylums, protectories and other institutions under local control and management. And though the state takes no part in the administration of these municipal and other local prisons, they are crowded with persons convicted of violating the laws of the state.

The county jails afford the most convincing proof (were any proof needed) of the unfitness of a municipal corporation to operate a prison. Some forms of cruelty were expelled from the modern prison, never to return, by John Howard and Elizabeth Fry; but most of the surviving abuses that are still found in the worst prisons in civilized countries now exist in our average county jail. Unsanitary conditions that are positively dangerous to life, insecurity against escapes, danger from fire, undue crowding from insufficiency of space, the absence of facilities needed for personal cleanliness and of accommodations required for common decency, the prevalence of vermin and of all filth and squalor, the absence of sunlight, and an all-pervading and nauseating stench - these are some of the features that characterize the buildings which are tused for the average county jail. The administration of the jails is even worse than their physical condition; the management of the jail is a perquisite of the sheriff of the county, who derives a large part of his income from the profits gained from boarding the prisoners and from extortions levied on the prisoners and their friends. Thus the jails are 
made the "spoils" of politics, and are exploited by each succeeding sheriff with the aim of extracting from their management for his own personal profit as large a pecuniary return as possible. The "plum" is too rich a one to be held by the same person longer than a single official term, and so the control is apt to be shifted to a newly elected sheriff at each successive election. Considerations wholly political control the selection of the successful candidate; uniformity, and even continuity, of administration and the establishment of reforms thus become practically impossible. Necessary appropriations for improving or rebuilding the jails are obtained with greater difficulty than appropriations for any other public purpose; the rottenness of the county jails seems to have spread a taint of demoralization throughout the whole community with reference to every measure affecting them. And so it is that the county jails in the United States, except in a very few isolated instances, remain in a condition as utterly reprehensible and abandoned now as prevailed a hundred years ago.

The worst features of the county jail, however, still remain to be stated. In all county jails, with a very few possible exceptions, all the prisoners are herded together, during the daytime, in a common yard or room, with unrestrained freedom of intercourse and converse; in some of the jails there is even an imperfect segregation between the male and female prisoners. Persons awaiting trial and persons convicted, the innocent and the guilty, the old and the young, the hardened criminal and the novice in crime, all are thrown together into enforced and promiscuous association. There is no labor or industrial occupation; even in states where the laws require that the prisoners in the county jail shall be kept at work, the counties fail to make appropriations for the introduction of labor; there is no instruction; there is no discipline, except rough, and sometimes brutal, measures against insubordination and violence. The corrupting effect of these conditions upon the inmates is so inevitable and so blighting as to justify the estimate, which has often been expressed, that the county jails are a more productive cause of crime in the United States than is the use of intoxicating liquor. 
The common designation of these jails as "nurseries of vice" and "schools of crime" is but a feeble characterization of their atrocities. To sentence any human being to imprisonment in a county jail is so sure to effect his moral deterioration that every such sentence is a distinct injury to society; it is nothing less than the promotion and fostering of crime by public authority.

Still, the institution of the county jail is firmly entrenched in the law and the politics of the country and all efforts to reform it have been, and are likely to be, futile. Its abuses are so radical and inveterate that there is no hope that it can ever be purged and rehabilitated. The only practicable remedy is to cease to use the jail at all as a place of confinement for persons convicted of crime. The invincible evils of the county jails and the urgent necessity of providing some substitute for them have brought into prominence the question, which is now being widely discussed, whether the state should not withdraw from the municipalities all power (heretofore delegated) to deal with offenders against state law, and itself assume the charge and custody of every person sentenced to imprisonment for crime. The reasons which have been already urged to show that this is the logical function and duty of the state gain added force from the position that there is no other practicable way of supplanting and suppressing the county jail.

The plan here advocated of bringing all convict prisoners under the central control of the state involves the acquisition of additional prisons by the state. In many cases the country penitentiaries and other local prisons could be purchased by the state and be rendered available for reformatory uses. The proposed change would doubtless necessitate in every state the construction and equipment of one or more entirely new prisons, and would unquestionably entail upon the state a largely increased initial expenditure. The municipalities, on the other hand, would be relieved of the expenditures they now incur from this cause. The increased expense might be, in whole or in part, apportioned by the state and assessed upon the municipalities in proportion to the number of convicts coming from each locality; this would put upon each municipality the incentive of self-interest to use vigi- 
lance in the suppression of vice and to purge itself of the criminal class. Whether the large expense here advocated can be justified on the ground of political economy depends upon the answers to be given to some very complicated questions: What is the direct and indirect cost of crime to a community? What would be the saving in money to a state if 80 or even 50 per cent. of its convicts were rescued from a life of crime and transformed into industrious and law-abiding citizens? In the light of experience, estimating the results that have been actually wrought by reformatory prisons, it is possible, by careful computation, to arrive at but one conclusion. The establishment of a reformatory prison, and its operation through skilled managers upon approved scientific methods, yield larger pecuniary returns to the public than the investment of an equivalent amount in any other public work whatsoever. It would not be difficult to prove that the pecuniary benefit gained by the people of the state of New York from the Elmira Reformatory has already far exceeded in amount all that the state has expended both in the erection and in the maintenance of that institution. ${ }^{1}$

Another objection that may be urged to the exclusive control of prisons by the state is the danger that they may be made the "spoils" of party politics. That is precisely the evil which has ruined the county jails, and which must always prove fatal to any prison or prison system brought under purely partisan control. There is only one way of meeting this evil, and that is by a system of efficient inspection and supervision, with power to correct abuses; and such supervision can be made efficient only by the support of an enlightened and alert public spirit. If all the prisons in the state were brought under a central and uniform control, the system on which they were managed would command a greatly increased importance and publicity; the obscure and petty jails now existing would be supplanted by great institutions, avowing large aims and claiming to be conducted on scientific principles; the public attention and interest would be arrested, and abuses which pass unnoticed and unknown in the local jails would become impossible under the administration of

${ }^{1}$ Cf. The Science of Penology, by Henry M. Boies, pp. 135, 16r. 
the state and in the full blaze of public opinion. The danger of partisan control, now seen at its worst in the county jails, would surely be greatly diminished, and there is ground to hope that it would entirely vanish before the increased publicity of a centralized state system, and the increase of public interest and enlightenment which such a system would inevitably foster.

What would then become of the buildings now used as county jails? Some of these are of such faulty construction, or so saturated with filth, or so impregnated with the germs of disease as to be wholly unfitted for any use and are only meet for destruction. Very many of the jail buildings, however, can be so repaired and altered as to make them available for use as places of detention for persons arrested under civil process, for witnesses in criminal cases, and for persons accused of crime and awaiting trial. And this brings us to the consideration of the proper treatment of that second class of prisoners, mentioned above; those, namely, who have been arrested on a charge or on suspicion of crime and are detained while awaiting trial.

2. Imprisonment before trial.- These prisoners form a class entirely distinct from guilty and convicted prisoners, and are entitled to receive a wholly different kind of treatment. The law presumes them to be innocent, and the law should treat them as if they were innocent. Their imprisonment has no other object than their safe custody until the question of their guilt or innocence can be judicially determined. There is, in their case, no occasion for any disciplinary or reformative training; they may be, and in many instances they are, wholly innocent, and, until they are actually adjudged guilty, they have all the rights of other members of the community, subject only to their enforced detention. To treat them as if they were criminals, to confine them in association with prisoners who are guilty and are serving sentence for crime, and thus to subject them to most corrupting influences, is much more than a mere personal outrage; it is a grievous wrong to the public whereby the authority of law is used to foster crime by keeping a presumably innocent person in enforced contact with criminals.

When a youthful offender is for the first time arrested for 
crime, it is the most critical turning-point in his life. He ought to be confined in solitude; then, if ever, his reflections will bring him to a realizing sense of his sin and folly, of the downward course he has been following, and, if continued, its inevitable end; he cannot but see that he stands at the parting of the ways; then, if ever, his better impulses will assert themselves and awaken within him new purposes to amend his life for the future. These beneficent meditations and resolutions, the present system, instead of promoting, does all that it can to stifle; it hurries the arrested person to the courity jail, and thrusts him into the midst of the vile company there congregated. There is no opportunity for quiet thought, no means of withdrawal into privacy; any natural manifestation of sorrow or depression is greeted with ribald taunts and jeers; the voice of conscience is drowned; the talk is of exploits in vice and crime; the air reeks with blasphemy and obscenity; the future is the subject of reckless derision. How is it possible that repentance or self-respect or any worthy purpose should thrive in such an environment?

The bad policy, as well as the grievous wrong, of confining an arrested person whether guilty or innocent (but in law presumably innocent), in enforced and unrestrained association with criminals is sufficiently obvious. But there is another consideration that should not be overlooked. Not only does the law presume innocence, but a very large majority of persons arrested are in fact not guilty. When a crime is committed, it often happens that several, and sometimes a good many, persons are arrested upon a suspicion of guilt which proves to be unfounded. Thus the number of arrests will always be found largely in excess of the number of convictions. In the city of New York there are five times as many arrests for felony as there are convictions; that is, for every person there found guilty of felony there are four other persons arrested on charge of felony who are not found guilty. ${ }^{2}$ It is a disgrace and an injury to reputation to be confined in a prison. The public does not stop to inquire whether the person imprisoned was really innocent or

${ }^{2}$ See tables of statistics in appendix of The Science of Penology, by H. M. Boies. 
guilty; the mere fact that he has been "in prison" places any man in an ambiguous position and creates, in the public estimation, a presumption against his character which is a distinct, and often a very serious, injury. This is a stain that ought not to be put upon any person arrested on a mere charge or suspicion of crime. Until found guilty, he should not be placed in the same category with convicts, and he should be confined in a "house of detention," and not in a "prison;" prisons and jails, penitentiaries and reformatories, should contain only adjudged criminals.

Confinement while awaiting trial is, as has already been said, a mere continuation of the arrest, and may well be committed to the charge of the municipality that made the arrest. None of the reasons which have been urged for placing all convicted prisoners in the exclusive custody of the state, to the end that they may be subjected to reformatory discipline, apply to persons under arrest while awaiting trial. On the contrary, the rightful distinction between the two classes ought to be emphasized, not only by confining them in different buildings called by different names and under wholly different régimes, but by the further difference that no arrested person shall be turned over to the state or be put in prison until after conviction; before conviction, he shall be confined in a house of detention under the charge of the municipality. Moreover, the management of a house of detention should be widely different from that of a prison. It should never be forgotten that any member of the community, no matter how upright and pure in character, is liable to be arrested at any time on a charge of serious crime; this may happen through the malice of enemies, through mistaken identity, through a fraudulent conspiracy of which he is the innocent victim, through false deductions from circumstantial evidence. The right of every arrested person to receive decent treatment must be recognized and enforced, and it is imperatively necessary that a stop should be put to the scandalous intermingling of the innocent and the guilty. Every person arrested should be confined alone in a separate apartment and should be treated in a manner consistent with the legal assumption that he is innocent 
of the crime of which he is accused. The municipalities have shown in so striking a way their incapacity to conduct a prison that one may well hesitate to commit the custody of anyone to their charge; such a course is here advocated only when coupled with the condition that the state enact laws prescribing with definite precision the character and appointments of the buildings in which arrested persons shall be confined and the manner in which they shall be treated. Nor is the mere enactment of laws sufficient; the duty should be laid upon a state board, or officers of the state, to keep these buildings under constant and rigid inspection, and to enforce all statutory enactments regarding their structure and management.

To summarize briefly the propositions here advocated: The salutary principle of home rule demands that municipalities should be invested with power to enact such ordinances as they may deem fitted to protect the interests of their inhabitants, with imprisonment as the penalty for infraction, subject to the limitations contained in their charters and subject to the general laws of the state. The municipal courts should have jurisdiction to try and to sentence persons accused of violating such ordinances, and persons so sentenced should be imprisoned in prisons maintained and operated by the municipality.

Municipalities should also be thrown upon their own responsibility to protect themselves against crime; and the duty of maintaining instrumentalities for the detection of crime and for the arrest of persons charged with any violation of law, whether municipal or state law, should rest upon the municipalities. Persons so arrested should be confined while awaiting trial in houses of detention under the control of the municipality.

The power of the municipality, however, to maintain prisons (for the incarceration of persons sentenced for violation of municipal ordinances) and houses of detention (for the custody of persons arrested and awaiting trial) should be made subject to strict limitations. Municipal prisons and houses of detention should be required to bear different names and to be distinct and separated in location from each other. The state should enact 
general laws relating to the construction of such buildings and the system on which they are to be conducted; and the power and duty should be vested in a state board or officers of the state to maintain a constant and rigid inspection of such buildings and of their management, and to enforce their conformity to the law.

All persons arrested upon a charge of violating state law should be brought to trial before state courts only, which should have exclusive jurisdiction in all such cases.

All persons found guilty of violating laws of the state and sentenced to imprisonment should be committed to the custody of the state, and sent to prisons under the exclusive control and management of the state.

All prisons should be conducted upon a reformatory basis, where every person sentenced to imprisonment shall be treated in accordance with those approved scientific methods which have resulted, and can be made to result, in the actual reformation of a majority of convicted offenders. When this consummation is reached - and it will only be after long and strenuous effort the volume of crime must steadily grow smaller and smaller, until it is reduced to a minute residuum of incorrigible and irreclaimable criminals (if such there are) who are beyond the reach of human effort and science. When the existence of such a residuum is demonstrated, its perpetual imprisonment seems the only efficient and practical measure of public defense. ${ }^{3}$

${ }^{3}$ For a very important application of the main principles of this paper to a concrete situation, see the valuable report of the Prison Commission to the governor of Indiana, December 26, 1904.- EDIToR. 